\title{
Mariana Trench fauna accumulate methylmercury produced in upper oceans
}

\author{
RUOYU SUN ${ }^{1 *}$, JiNGJING YUAN ${ }^{1}$, JEROEN E. SONKE ${ }^{2}$, \\ WANG ZHENG $^{1}$, MEI MENG ${ }^{1}$, JIUBIN CHEN $^{1}$, Yi LIU ${ }^{1}$, \\ XIAOTONG PenG ${ }^{3}$, CongQing LiU ${ }^{1}$ \\ ${ }^{1}$ Institute of Surface-Earth System Science, Tianjin \\ University, Tianjin 300072, China (*correspondence: \\ ruoyu.sun@tju.edu.cn) \\ ${ }^{2}$ Laboratoire Géosciences Environnement Toulouse, \\ CNRS/IRD/Université Paul Sabatier Toulouse 3, France \\ ${ }^{3}$ Deep Sea Science Division, Institute of Deep Sea Science \\ and Engineering, Chinese Academy of Sciences, Sanya, \\ Hainan 572000, China
}

Monomethylmercury (MMHg) is a potent toxin that bioaccumulates and magnifies in marine food webs. Investigating where and how MMHg is produced in oceans is critically important to understand global $\mathrm{Hg}$ cycling and human exposure. Currently, the exact origin of MMHg in seawater is not well known. What we have learned over the past decade is that $\mathrm{MMHg}$ is produced in the oxygen minimum zone of all major oceans, most likely by microbes feeding on sinking organic particles, but possibly by abiotic means. Surprisingly field studies also observed abundant MMHg in deep oceans, but are uncertain of its origins: downwelling of MMHg produced in upper oceans vs. in-situ MMHg production in deep oceans.

During 2016-2017, we deployed sophisticated deep-sea lander vehicles on the seafloor of Mariana and Yap trenches, amongst the most remote and inaccessible locations on Earth, and captured the endemic fauna (amphipod and snaifish) at $7000-11000 \mathrm{~m}$ and collected sediments at $5500-9200 \mathrm{~m}$. We measured $\mathrm{Hg}$ concentrations and $\mathrm{Hg}$ isotope compositions in sediments and fauna. The trench fauna at $7000-11000 \mathrm{~m}$ depth all have substantially positive mass-independent fractionation of odd $\mathrm{Hg}$ isotopes (odd-MIF; $\Delta^{199} \mathrm{Hg}=1.47 \pm$ $0.13 \%, \Delta^{201} \mathrm{Hg}=1.21 \pm 0.11 \%$, $\left.1 \mathrm{SD}\right)$, which can be generated only in the photic zone via MMHg photodegradation. Given the identical odd-MIF in trench fauna and North Pacific upper ocean biota $\mathrm{MMHg}\left(\Delta^{199} \mathrm{Hg}=1.44\right.$ $\pm 0.75 \%$, $\Delta^{201} \mathrm{Hg}=1.16 \pm 0.60 \%$, $\left.1 \mathrm{SD}\right)$, we suggest that the accumulated $\mathrm{Hg}$ in fauna originates exclusively from $\mathrm{MMHg}$ produced in upper oceans, which penetrates to depth by sorption to sinking particles. Our findings reveal little in-situ $\mathrm{MMHg}$ production in deep oceans, and imply that anthropogenic $\mathrm{Hg}$ release at the Earth's surface is much more pervasive across deep oceans than was previously thought. 